\title{
ANALISIS PENDAPATAN DAN PROFITABILITAS USAHA TERNAK AYAM PEDAGING KECAMATAN CLUWAK KABUPATEN PATI
}

\author{
P. M. Puspita ${ }^{1}$, S. I. Santoso² dan W. Sarengat ${ }^{2}$ \\ 1) Mahasiswa Fakultas Peternakan Dan Pertanian Universitas Diponegoro \\ Kampus drh. Soejono Koesoemowardojo Tembalang Semarang 50275 \\ 2) Fakultas Peternakan dan Pertanian, Universitas Diponegoro \\ Kampus drh. R. Soejono Kusumowardojo Tembalang, Semarang 50275
}

Diterima: 25 Januari 2016

Disetujui: 20 Oktober 2016

\begin{abstract}
ABSTRAK
Sebuah penelitian bertujuan untuk mengetahui besarnya biaya produksi, penerimaan dan pendapatan usaha serta untuk mengetahui tingkat profitabilitas pada usaha peternakan ayam pedaging di Kecamatan Cluwak Kabupaten Pati. Penelitian ini dilaksanakan di Peternakan ayam pedaging di Kecamatan Margoyoso Kabupaten Pati. Metode pengumpulan data dalam penelitian ini menggunakan metode wawancara dan observasi (pengamatan). Jenis data dikumpulkan adalah data primer dan data sekunder. Data primer diperoleh melalui pengamatan langsung dan hasil wawancara dengan menggunakan kuesioner mengenai aspek teknis dan keuangan. Data primer berupa data "Time Series" selama bulan Januari-Desember 2014. Analisis kuantitatif diuji menggunakan one sample t-test, untuk membandingkan nilai profitabilitas terhadap suku bunga deposito perbankan. Berdasarkan hasil penelitian pendapatan bersih usaha peternakan ayam broiler di Kecamatan Cluwak pada tahun 2014 mencapai $\mathrm{Rp}$ 40.998.101. Nilai profitabilitas yang dicapai pada tahun 2014 sebesar 7,52\%. Berdasarkan one sample t-test perbandingan profitabilitas dengan suku bunga deposito perbankan, menunjukkan hanya terdapat satu perusahaan dari 5 perusahaan inti yang berbeda nyata $(\mathrm{P} \leq 0,05)$, sedangkan keempat yang lain tidak berbeda nyata $(\mathrm{P}>0,05)$. Simpulan yang diperoleh dari penelitian ini adalah Profitabilitas sebagian besar peternak plasma dari seluruh perusahaan inti di Kecamatan Cluwak menghasilkan keuntungan melalui angka profitabilitas yang lebih besar dibanding suku bunga deposito bank.
\end{abstract}

Kata kunci: ayam pedaging, pendapatan, profitabilitas 


\title{
THE ANALYSIS OF INCOME AND PROFITABILITY OF ENTERPRISES BROILER IN CLUWAK DISTRICT OF PATI REGENCY
}

\begin{abstract}
A study aims to determine the cost of production, revenues and incomes as well as to determine the level of profitability in broiler chicken farm in the district Cluwak Pati Regency. This research was conducted at the Broiler farm in District Margoyoso Pati Regency. Methods of data collection in this study using interviews and observation (observation). The type of data collected primary data and secondary data. The primary data obtained through direct observation and interviews with questionnaires regarding technical and financial aspects. Primary data is data "Time Series" during the months from January to December 2014. The quantitative analysis was tested using a one-sample t-test, to compare the profitability towards of the bank deposit interest rate. Based on the research net income of broiler chicken farm in the Cluwak district in 2014 reached $R p$ 40,998,101. Value of profitability achieved in 2014 amounted to 7.52\%. Based on one sample t-test comparison of the profitability of the bank deposit interest rate, suggests there is only one company from 5 enterprise real which significantly different $(P \leq 0,05)$, while the other four are not significantly different $(P>0.05)$. The conclusions obtained from this study are mostly farmers profitability plasma from whole core companies in the District Cluwak generate profits through numbers greater profitability than bank deposit rates.
\end{abstract}

Keywords: broiler chicken, income, profitability

\section{PENDAHULUAN}

Ayam broiler merupakan salah satu komoditas peternakan yang mempunyai peran penting dan substansial dalam memenuhi kebutuhan produk hewani dalam negeri. Permintaan produk hewani terutama daging meningkat seiring meningkatnya jumlah penduduk, tingkat pendapatan, dan kesadaran masyarakat terhadap gizi. Hal ini menyebabkan perlu adanya peningkatan jumlah produksi guna memenuhi permintaan tersebut. Pengembangan jumlah populasi ayam broiler di Indonesia sangat diperlukan untuk memenuhi kebutuhan daging yang semakin meningkat. Pengembangan ini dapat dilakukan dengan sistem mandiri maupun dengan kemitraan.
Kecamatan Cluwak merupakan salah satu kecamatan yang ada di wilayah Kabupaten Pati yang mempunyai populasi ayam broiler cukup besar dengan skala kepemilikan kecil untuk setiap peternaknya. Data Dinas Pertanian dan Peternakan Kabupaten Pati (2014) menunjukkan bahwa jumlah peternak ayam broiler yang ada di wilayah Kecamatan Cluwak menyumbang $23 \%$ dari populasi ayam pedaging Kabupaten Pati dengan populasi 145.800 ekor. Kecamatan Cluwak mempunyai potensi sebagai sentra pengembangan ayam pedaging untuk Kabupaten Pati melalui keadaan geografis yang masih berupa lahan-lahan kosong di lereng gunung Muria. Usaha peternakan ayam broiler di Kecamatan Cluwak banyak dilaksanakan dengan 
sistem kemitraan (inti-plasma) dengan rentang skala populasi antara 2500-5000 ekor.

Tujuan dari penelitian ini adalah untuk mengkaji tingkat profitabilitas yang diperoleh peternak ayam broiler yang mengikuti pola kemitraan yang berbeda di daerah Kecamatan Cluwak, Kabupaten Pati. Manfaat dari penelitian ini yaitu dapat memberikan informasi kepada peternak tentang hasil analisis profitabilitas yang diperoleh dalam menjalankan usaha peternakan ayam broiler dengan pola kemitraan dan mengetahui apakah usaha peternakanya menguntungkan (profitable) atau tidak.

\section{MATERI DAN METODE}

Penelitian ini dilaksanakan di Peternakan ayam pedaging di Kecamatan Cluwak Kabupaten Pati. Responden dari Penelitian ini adalah karyawan dan pemilik peternakan ayam pedaging di Kecamatan Cluwak. Metode pengumpulan data dalam penelitian ini menggunakan metode wawancara dan observasi (pengamatan). Jenis data dikumpulkan adalah data primer dan data sekunder. Data primer diperoleh melalui pengamatan langsung dan hasil wawancara dengan menggunakan kuesioner mengenai aspek teknis dan keuangan. Data primer berupa data "Time Series" selama bulan Januari-Desember 2014. Data yang sudah terkumpul selanjutnya diedit, ditabulasi dan dianalisis secara deskriptif dan kuantitatif. Analisis kuantitatif diuji menggunakan one sample t-test, untuk membandingkan antara nilai profitabilitas dengan suku bunga deposito bank yang berlaku.

\section{HASIL DAN PEMBAHASAN \\ Keadaan Umum}

Kecamatan Cluwak merupakan salah satu dari 21 kecamatan yang berada di wilayah Kabupaten Pati. Jumlah responden yang diambil pada penelitian ini sebanyak 40 orang peternak dengan lima perusahaan inti. Perusahaan inti tersebut diantaranya PT Patriot Panca Prima (PPP), PT Telur Intan Kudus Farm (TKF), CV Super Chick (SC), PT TJL dan PT Indo Chick (IC). Skala usaha peternakan kemitraan ayam pedaging di Kecamatan Cluwak mencapai 2500-5000 ekor.

Berdasarkan data produktifitas pada tahun 2014 menunjukkan bahwa rata-rata FCR yang dicapai peternak dari perusahaan inti PT PPP, PT TKF, CV SC, PT TJL dan PT IC secara berturut-turut mencapai 1,69 ; 1,$65 ; 1,65 ; 1,66$ dan 1,68. Hal ini menunjukkan bahwa tingkat efisiensi pakan dari seluruh perusahaan inti cukup baik. Angka FCR yang dicapai peternak di Kecamatan Cluwak masih lebih rendah dibanding standar FCR menurut Suwianggadana et al. (2013) yaitu sebesar 1,70 pada bobot badan rata-rata $1,75 \mathrm{~kg}$. Nilai FCR yang tinggi dipengaruhi oleh kondisi ayam, pakan, dan lingkungan kandang.

Tingkat mortalitas peternakan ayam pedaging di Kecamatan Cluwak pada perusahaan inti PT PPP, PT TKF, CV SC, PT TJL dan PT IC secara berturut-turut mencapai 4,57; 4,39; 4,07; 6,07 dan 5,22\%. Indeks Prestasi dari seluruh perusahaan inti cukup baik karena nilainya sudah melebihi 300. Hal ini sesuai dengan pendapat Tamalluddin (2014) yang menyatakan bahwa standar IP yang baik yaitu di atas 300, semakin tinggi nilai IP semakin berhasil suatu pemeliharaan ayam broiler. Cepriadi et al. (2010) menyatakan bahwa IP sangat bergantung pada nilai FCR dan periode pemeliharaan, karena semakin besar nilai FCR dan semakin lama ayam dipanen akan mengakibatkan semakin besar nilai IP yang dapat menurunkan insentif yang diterima oleh peternak. 


\section{Pendapatan}

Pendapatan peternak plasma diperoleh dari selisih antara total penerimaan dengan biaya produksi yang dikeluarkan. Rata-rata pendapatan peternak plasma di Kecamatan Cluwak dapat dilihat pada Tabel 1.

Tabel 1. Pendapatan Peternak Plasma Selama Satu Tahun

\begin{tabular}{llrrrr}
\hline \hline No. & Perusahaan Inti & Rata-rata Populasi & Penerimaan & Biaya Produksi & Pendapatan \\
\hline & & --Ekor-- & ------------ Rp--------- \\
1. & PT PPP & 16786 & 543.837 .243 & 497.957 .006 & 45.880 .238 \\
2. & PT TKF & 19397 & 623.441 .109 & 587.501 .833 & 35.939 .275 \\
3. & CV SC & 16907 & 534.969 .534 & 487.599 .111 & 47.370 .423 \\
4. & PT TJL & 21364 & 658.691 .878 & 625.989 .562 & 32.702 .316 \\
5. & PT IC & 20980 & 674.712 .177 & 631.613 .925 & 43.098 .252 \\
\hline
\end{tabular}

Sumber : Data primer yang diolah (2015).

Berdasarkan Tabel 1. dapat dilihat bahwa pendapatan paling tinggi diperoleh peternak dari CV SC yaitu sebesar Rp. 47.370.423,-, sedangkan pendapatan yang paling rendah diperoleh peternak dari PT TJL dengan nilai Rp. 32.702.316,-. Hal ini disebabkan mortalitas dan biaya produksi CV SC lebih rendah dibanding perusahaan inti yang lain dengan 4,07\% dan Rp. 487.599.111. Hasil ini menunjukkan bahwa tingkat kematian dan biaya produksi untuk tiap periode berperan penting dalam menghasilkan pendapatan karena tingkat kematian menunjukkan jumlah populasi yang akan dipanen. Hasil ini sesuai dengan hasil penelitian Rizki (2012) yang menunjukkan bahwa tingkat mortalitas ayam broiler dapat mempengaruhi fluktuasi tingkat FCR dan akan berpengaruh pada tingkat pendapatan peternakan ayam broiler. Pambudi et al. (2013) menyatakan bahwa nilai mortalitas yang rendah secara tidak langsung akan menambah pendapatan melalui penanganan penyakit baik melalui pengobatan dan vaksinasi. Suryana (2013) menyatakan bahwa analisis pendapatan dari suatu usaha dapat dihitung berdasarkan selisih antara total penerimaan dengan total biaya.

\section{Profitabilitas}

Profitabilitas menggambarkan kemampuan suatu perusahaan dalam memperoleh laba melalui semua kemampuan dan sumber daya yang ada. Besarnya profitabilitas peternak plasma di Kecamatan Cluwak dapat dilihat pada Tabel 2.

Tabel 2. Profitabilitas Peternak Plasma Selama Satu Tahun.

\begin{tabular}{|c|c|c|c|c|c|}
\hline No & $\begin{array}{c}\text { Perusahaan } \\
\text { Inti }\end{array}$ & Pendapatan & $\begin{array}{c}\text { Pajak } \\
\text { Penghasilan }\end{array}$ & $\begin{array}{c}\text { Pendapatan } \\
\text { Bersih }\end{array}$ & Profitabilitas \\
\hline & & & ----Rp------- & (--- & ----\%---- \\
\hline 1. & PT PPP & 45.880 .238 & 458.802 & 45.421 .435 & 9,78 \\
\hline 2. & PT TKF & 35.939 .275 & 359.393 & 35.579 .883 & 6,59 \\
\hline 3. & CV SC & 47.370 .423 & 473.704 & 46.896 .719 & 9,35 \\
\hline 4. & PT TJL & 32.702 .316 & 327.023 & 32.375 .293 & 5,29 \\
\hline 5. & PT IC & 43.098 .252 & 430.983 & 42.667 .269 & 6,60 \\
\hline
\end{tabular}

Sumber : Data primer yang diolah (2015). 
Berdasarkan Tabel 2. dapat diketahui bahwa nilai profitabilitas peternak plasma pada PT TJL paling rendah yaitu sebesar 5,29\% sedangkan peternak plasma pada PT PPP mempunyai nilai profitabilitas paling tinggi yaitu sebesar 9,78\%. Hal ini menunjukkan bahwa peternak pada PT PPP mempunyai kemampuan menghasilkan laba paling baik dibandingkan peternak pada perusahaan inti yang lain. Nilai profitabilitas para peternak dari PT PPP, PT TKF, CV SC dan PT IC lebih tinggi dibandingkan dengan suku bunga deposito bank BNI yang berlaku selama 1 tahun pada tahun 2014 yaitu sebesar 5,50\%. Hal ini meunjukkan perusahaan peternakan tersebut dapat dikatakan mampu menghasilkan keuntungan dengan baik. Akan tetapi PT TJL mempunyai profitabilitas lebih rendah dibanding suku bunga deposito bank BNI dengan 5,29\%. Hal ini dikarenakan tingginya biaya produksi yang dikeluarkan, yang disumbang oleh biaya penyusutan kandang dan rendahnya penerimaan yang diakibatkan oleh tingginya angka mortalitas jumlah panen. Menurut Ibrahim (2003), semakin besar profitabilitas dari suatu usaha menunjukkan bahwa semakin baik kemampuan usaha yang dijalankan dalam menghasilkan keuntungan. Profitabilitas yang bervariasi dari tiap-tiap inti disebabkan karena nilai kontrak yang berbeda-beda dari masing-masing inti. Besarnya nilai profitabilitas yang dicapai dari peternak plasma dari setiap inti menunjukkan kemampuan dalam menghasilkan laba. Hasil profitabilitas pada penelitian ini lebih tinggi dibanding hasil penelitian Utomo et al. (2015), yang menyatakan bahwa profitabilitas peternakan ayam pedaging dengan pola kemitraan di daerah Kecamatan Limbangan Kabupaten
Kendal mencapai 4,79\% dengan jumlah populasi 4000-8000 ekor.

Berdasarkan hasil analisis yang disajikan pada Tabel 7. dapat dilihat bahwa PT PPP mempunyai taraf signifikasi 0,050. Artinya adalah $\mathrm{H}_{0}$ ditolak dan $\mathrm{H}_{1}$ diterima karena nilai signifikansi $\leq 0,05$. Hal ini menunjukkan bahwa tingkat profitabilitas PT PPP berbeda nyata dengan suku bunga deposito bank yang berlaku. Hal ini disebabkan karena adanya perbedaan yang cukup besar antara nilai profitabilitas dengan suku bunga deposito bank. Akan tetapi PT TKF, CV SC, PT TJL dan PT IC mempunyai taraf signifikasi $>0,050$, yang berarti tidak ada perbedaan nyata antara nilai profitabilitas dengan suku bunga deposito bank yang berlaku.

\section{SIMPULAN DAN SARAN \\ Simpulan}

Simpulan dari penelitian ini adalah Profitabilitas sebagian besar peternak plasma dari seluruh perusahaan inti di Kecamatan Cluwak menghasilkan keuntungan melalui angka profitabilitas yang lebih besar dibanding suku bunga deposito bank.

\section{Saran}

Untuk menghasilkan keuntungan dari modal uang yang dimiliki, bagi peternak di Kecamatan Cluwak, lebih baik modal digunakan untuk beternak secara plasma daripada membungakan modal tersebut di deposito bank, karena sebagian besar peternak plasma dari seluruh perusahaan inti di Kecamatan Cluwak mampu menghasilkan keuntungan melalui angka profitabilitas yang lebih besar dibanding suku bunga deposito bank. 
DAFTAR PUSTAKA

Cepriadi, E. Maharani dan N. Maureen. 2010. Analisis perbandingan pola kerjasama kemitraan peternak ayam broiler di kota Pekanbaru (Studi Kasus PT. Ramah Tamah Indah). Jurnal Peternakan 7 (1):20-27.

Ibrahim, Y. 2003. Studi Kelayakan Bisnis. Rineka Cipta, Jakarta.

Pambudi, T. R. O. D. Edy dan N. N. Hidayat. 2013. Analisis keuntungan dan rentabilitas usaha ayam niaga pedaging (studi kasus pada kemitraan ismaya unggas makmur di Kabupaten Kebumen). Jurnal Ilmiah Peternakan 1 (3): 1128-1135.

Rizki, A 2012. Analisis Risiko Produksi Ayam Broiler pada Peternakan Bapak Maulid di Kelurahan Karang Anyar Kecamatan Bukit Baru Kota Palembang. Skripsi. Fakultas Ekonomi dan Manajemen, Institut Pertanian Bogor.

Suryana. 2013. Kewirausahaan, Kiat dan Proses Menuju Sukses. Salemba Empat, Jakarta.

Suwianggadana, I. P. A., Suciani, dan N. P. Sariani. 2013. Analisis finansial usaha peternakan ayam pedaging dengan pola kemitraan. Peternakan Tropika 1 (2):58 - 68.

Tamalludin, F. 2014. Panduan Lengkap Ayam Broiler. Penebar Swadaya, Jakarta.

Utomo, H.R., H. Setiyawan dan S.I. Santoso. 2015. Analisis profitabilitas usaha peternakan ayam broiler dengan pola kemitraan di kecamatan Limbangan kabupaten
Kendal. Animal Agriculture Journal, 4 (1):7-14. 